\title{
Difficult Parents Make Me Feel Good: A Narrative on Reflective Teaching Practice
}

\author{
Craig Geddes
}

\begin{abstract}
This article refers to the complex nature of the practice of teaching with specific reference to the (sometimes) unpleasant task of dealing with high-demand parents. Because many aspects of teaching practice are beyond the immediate control of the teacher, there is utility in discussing how difficult circumstances can be understood in ways that add value to teaching practice, rather than allowing such circumstances to remain negative at the risk of accumulating more and more frustration in one's teaching practice. The article focuses on how to maintain a positive outlook while going through what could be considered to be negative experiences. Three hypothetical scenarios are presented. The author has taught at the elementary, middle, secondary and postsecondary levels in the Greater Vancouver area, and is currently a doctoral candidate at Simon Fraser University.
\end{abstract}

If you are startled by the title above, you have very likely experienced the full magnitude of a somewhat less-than-positive interaction with the parent or parents of a student under your tutelage. If you have been in education for any length of time it is even more likely that you have had the ignominious distinction of multiple experiences of this nature. If you find the previous statement paradoxical in light of the title then you should probably continue reading, as I will attempt to explain how I have come to an existential and practical location that allows me to construct a positive experience out of what so many others justifiably experience as distasteful, unpleasant, or even as extremely upsetting.

I do not claim any particular expertise in dealing with parents in the best or most appropriate manner - but only that I have figured out a way to deconstruct and positively reconstruct the interactions I have had with what teachers or administrators might consider to be difficult parents. I must also clearly acknowledge that much of what I now know (about the current topic) has come to me over the course of my ongoing thirteen-year public school teaching career, and it has come to me mostly through the process of introspection, rather than as an evaluative or judgmental process based on analyzing my colleagues' interactions with parents - although I have learned from those as well. My next caveat is that, while the title of this article refers to what is commonly understood to be a negative experience, the vast majority, and indeed virtually all, of my parental interactions have been of a positive nature. In what follows I will try to explain how this has come to be, with the intent that readers may possibly take something away from my narrative to use in a positive manner in their own practice.

In explaining what this article is about I must also state what it is not about. This is not a manual, checklist, or step-by-step self-help program for dealing with tough 
situations in teaching, although I will refer to some of these documents - and there are a good number of them out there (see Jaksec, 2005; McConkey, 1985). I must also locate this narrative within the myriad of possible parental interactions that can occur at any given moment of any given day (another phenomenon that distinguishes our profession from many others). These interactions range from the mundane to the sublime, from routine to completely unexpected, from forgettable to aggressive and potentially violent. As these last two scenarios are exceedingly rare, and I have no experience with either, I will focus on those interactions more closely related to the middle of the spectrum those that can possibly occur several times in a school year, or over the course of several years. In my particular context, parents identified as such are sometimes considered to be High Maintenance Parents, or H.M.P.s to use the local nomenclature (T.L.A). ${ }^{1}$ You may understand these parents to be overzealous child advocates, persistent parents, or difficult/problem parents. Left alone at this stage, such labeling of parents can be highly problematic, as it can clearly lead to the entrenchment of established positions, and hence be counterproductive to the facilitation of a more functional relationship between parents and teachers. However, recognizing that a particular parent or set of parents may require special attention can be a positive step toward reflective practice and also a step forward in cultivating better relations between parents and teachers. This will be explained further below.

Teaching and learning are immensely complicated phenomena that occur within and around multiple spheres of impact and influence. This is a fancy way of saying that the occupation of teaching can be exceedingly challenging at times. Hargreaves and Fullan (2012) undoubtedly agree:

Teachers might have admirable goals and expectations for themselves - to make a difference in children's lives, perhaps, or to inspire them to take up a new field of study - but they are constantly assailed with other people's goals and expectations too - to raise test scores, appease pushy parents, keep to the basics, turn everything around in one year or less, or implement the latest pet programs. If teachers are lucky, they will have excellent leaders who support them. Less fortunate ones will have leaders who are incompetent, indifferent, controlling, or corrupt; leaders who pay more attention to the mandates of their superiors than to the needs of their teachers and students; or revolving-door leaders who get fired or move on whenever the going gets too tough (Hargreaves \& Fullan, 2012, p. 30).

This excerpt is rather more cynical than most of the rest of Hargreaves and Fullan's excellent book, Professional Capital: Transforming Teaching in Every School. Two concepts are abundantly clear in the quotation above: teaching is an extremely complex endeavour, and many of the circumstances encountered by teachers are outside the limitations of their own control. If you happen to be a teacher in a jurisdiction such as British Columbia, a decade of labour unrest and chronic underfunding simply adds to the list of items beyond one's control.2

${ }^{1}$ T.L.A. stands for Teachers Love Acronyms.

2 This statement is based on the overwhelming majority of unionized public school teachers voting in support of job action in multiple voting opportunities over the last ten years in British Columbia. 


\section{Some Epistemologies}

...a sea change in cultural studies has eroded once-dominant conceptions of truth and objectivity. The truth of objectivism - absolute, universal, and timeless - has lost its monopoly status. It now competes, on more nearly equal terms, with the truths of case studies that are embedded in local contexts, shaped by local interests, and colored by local perceptions. The agenda for analysis has shifted to include not only eternal verities and lawlike generalizations but also political processes, social changes, and human differences. Such terms as objectivity, neutrality, and impartiality refer to subject positions once endowed with great institutional authority, but they are arguably neither more nor less valid than those of more engaged, yet equally perceptive, knowledgeable social actors (Rosaldo, 1993, p.21).

While this is a quotation borrowed from the social sciences (anthropology to be specific), it is highly relevant to education because it contains the acknowledgment of two things that, while they should be embraced and celebrated, at times are used as sources of contention. The two things to which I refer are the notions that:

1) Knowledge is constructed, subjective, and continually re-constructed.

2) We exist as active participants in this constructive process.

Winschitl (2000) provides a simple and effective definition of the way that a constructivist perspective can be understood:

.... constructivism is premised on the belief that learners actively create and restructure knowledge, constantly comparing ideas introduced in formal instruction to their existing knowledge, which has been assembled from personal experiences, the intellectual, cultural, and social contexts in which these ideas occur, and a host of other influences that serve to mediate understanding.

When learners make sense of the world, they are in fact creating knowledge. A central aim of constructivist culture is cultivating learners who believe that they can create knowledge themselves, and that knowledge does not exist outside them as some objective, universal entity (Windschitl, 2000, p. 99).

Somehow, the very ways we try to be effective as teachers are lost on ourselves before, during and after any sort of heightened state of interaction. If we agree with Dewey (1916), Piaget (1963), Bruner (1996), Vygotsky (1979) or any other of a multitude of theorists and practitioners who propose that constructivist methods are generally effective for teaching and learning, why then can we not apply these same principles to ourselves? Of course we can apply constructivism, or what social scientists refer to as social construction, to our own learning and to our own experiences. In substituting the teacher for the learner within a constructivist paradigm, the teacher (now the learner) can start to de-construct certain experiences that may have been negative or difficult, and re-construct those same experiences in a way that enriches one's practice, rather than impeding one's practice through the process of continually piling up negative 
experiences without ever having found the positives within those experiences. It is through reflection, looking back at a situation, and introspection, critically analyzing what that situation meant to me, that I can begin the process of reflective teaching practice. As is the case with many things in life, the more one engages in an activity, the higher one's capacity to engage effectively in that activity goes. This is what reflective teaching practice means to me. This link between a constructivist teaching and learning model and reflective teaching practice will also be illustrated below in three scenarios involving teacher/parent interaction.

In The Difficult Parent: An Educator's Guide to Handling Aggressive Behavior, Jaksec (2005) posits that while confrontation can lead to agency in a positive way, more often it elicits reactions more akin to defensive entrenchment:

Confrontation is a powerful tool, because, when used properly, it allows another individual to consider the effects of his or her behavior. Unfortunately, as many educators discover, confrontation with an overly aggressive parent usually produces little in the way of positive results. Parental aggression also comes in many forms, including physical or verbal. In addition, threats such as the invasion of personal space or gestures made in an effort to intimidate also constitute types of aggression (Jaksec, 2005, p. 5).

Once again, it is not toward violent or aggressive interactions that I focus here, but rather the lower level problematic interactions that can potentially occur on a more regular basis - ones that I have seen to be quite upsetting to myself (in the past) and to many other of my colleagues. Jaksec (2005) also explains the futility of such interactions:

Who are the real 'losers' as the result of these encounters? Quite possibly the students, because, in all likelihood, they will learn the same negative styles of communication as their parents. The parents, though, also suffer because their poor manner of communication might interfere or delay a solution to the problem facing their own child. In addition, the educators lose because these turbulent encounters have a cumulative effect, which might possibly affect their performance (Jaksec, 2005, p. 8).

While there are some notions implicit within the quotation that I don't necessarily support, it does resonate with me as I recall a student's plea to her dad during an interaction I had with a very persistent parent. She said, "Please stop - I don't want my teacher to hate me."3 I didn't know it during the confrontation, but this would become a seminal moment in the evolution of my ability to practice in a highly reflective manner. Only minutes after the event occurred I began to reflect and scrutinize the position I had taken. In so doing I was undertaking a very genuine positional analysis (reflection) with regards to whether I truly believed in the position I had taken, or whether I had simply dug in my heals to defend my position. Because I

3 Two things should be noted here. 1) This particular interaction played a very influential role in the philosophical position taken in this article, and 2) the student was made to understand clearly that neither her nor her father were hated by me. 
was actually prepared to change my position, I saw tremendous utility in the critical analysis I had started to subject myself to. In this case I re-confirmed my original position. The value of this type of reflective practice inheres within the practice of reflection itself, coupled with the willingness to change one's practice. I am thankful that this particular parent helped me realize that practicing reflection can lead to growth regardless of the degree of negativity associated with the circumstances being reflected upon.

\section{Parent Involvement}

Just as I attempted to (sort of) avoid the post-modernist dialectic arguments regarding constructivism versus positivism 4 , I will also shy away from evaluative judgment for or against parent involvement in children's education because, once again, there already exists a tremendous amount of research that suggests that higher levels of parental involvement are associated with higher levels of student achievement. And while this may be the case, it is unclear to me whether this is a causal link between participation and achievement, or merely a correlational link that is more appropriately explained using variables such as socio-economic status, ethnicity, parental occupation or any other significant variable influencing a student's learning experiences. Suffice it to say that I believe that parental involvement is valuable, necessary, and highly variable in its nature and frequency. For conceptual purposes I provide the following table describing parental involvement. In the table 'presence' refers to the number of interactions between a parent and a teacher (personal, phone call, email, etc.), and 'demand' refers to the nature of those interactions:

\begin{tabular}{|l|l|}
\hline 1. HIGH PRESENCE/LOW DEMAND & 2. HIGH PRESENCE/HIGH DEMAND \\
\hline 3. LOW PRESENCE/LOW DEMAND & 4. LOW PRESENCE/HIGH DEMAND \\
\hline
\end{tabular}
Table 1. Parental Presence and Demand.

At first glance quadrant 3 might appear to describe the most desirable state of teacher/parent interaction. 5 Wouldn't your life as an administrator or teacher be simpler if all parents fit conveniently into this category? Even the helicopter parent from quadrant 1 is a reasonable alternative, as they are still perceived as a person of low demand. It is the right side of the table that seems to present, on the surface, the more problematic interactions typical of parents labeled or perceived as difficult. Clearly quadrant 2 stands out as the category that should be avoided, if at all possible. What I am suggesting here is two-fold; the reality is that teachers and administrators will necessarily interact with parents from all four quadrants on numerous occasions (in fact, the same parent may even change quadrants on a temporal basis), and because of this we must learn to appreciate, and to properly deal with, parents from all of these categories. It is possible to do so.

\footnotetext{
4 Positivism is a philosophy that understands knowledge through a perspective of objectivity. It is often associated with a strict adherence to deductive, quantitative scientific method. Knowledge can be understood by anyone who chooses to observe the rules of proper methodology.

5 It should be understood that these categories reflect teacher perceptions of parental interaction/involvement, rather than any true or empirical state of reality.
} 


\section{Three Scenarios}

In this section I will describe three hypothetical scenarios as mini case studies. Scenario 1 begins with a father who has already been labeled as difficult by the teacher, and whose impending visit is easily and regrettably predicted. We know he is coming because he wants his daughter, who is an excellent basketball player, to play for the local secondary school's grade 9 team, even though she is currently enrolled in grade 8 at middle school. This parent can well and truly be understood to exist within the feared quadrant 2 above. He is a frequent visitor to the school and he is often quite demanding. The ethical dilemma faced by the middle school Athletic Director (A.D.) is this; should the A.D. sign for consent to be given for the student to play for the high school, knowing that this parent will likely not give up until it is - even though the middle school athletic association is philosophically opposed to players playing 'up' beyond their school levels? Even though signing consent would simply make the problem go away, and in all likelihood the player would be just fine on the secondary team, the A.D. did not sign consent. In spite of numerous and frequent correspondence from the player's parents questioning the A.D.'s judgment, she did not relent in her adherence to the athletic association philosophy that players should play with their school-level peers.

The more difficult path was also a more reflective path. Because the simple resolution involved just signing consent for the player to play up, by its very nature this pathway involved less introspection (not to mention contravention of the athletic association's guiding principles). However, the A.D. took the opportunity to reflect on why the athletic association held these values, and also on how these values aligned (or did not) with her own personal values. This process of introspection is part of the very essence of reflective practice that all educators should practice regularly. The net result of this interaction was not frustration or the perceptual addition of yet another difficult parent to 'the list,' rather it was a positive affirmation of some of the deeply-held values both of the athletic association and of the A.D. herself. This was not a simple case of the A.D. 'digging in her heels.' Herein lies the theoretical link between the scenario and a constructivist perspective on reflective practice. The A.D. de-constructed what could have been considered quite a negative experience, and then re-constructed the experience as one that positively affirmed the position she had taken. As long as the teacher's interactions with the parent remain on a respectful and professional level, what would appear to be a negative experience can actually be a positive one.

Scenario 2 may also conjure up recurring nightmares of that category of parents well known to be extremely critical of educators. Of course I am referring to those parents who are themselves teachers. This is clearly unfair and unwarranted as the majority of teachers are parents as well, and the majority of them do not fall into the high presence/high demand category (they are often too busy with other peoples' children). Recall, however, that we are dealing with perception, which is a powerful sense that guides our judgment. 
In this scenario, a highly effective and competent teacher is visiting his son's P.E. teacher to get clarification on how the third term P.E. marks were determined. This particular parent also happens to have over twenty years of experience as a P.E. teacher, in addition to possessing an expert knowledge of the P.E. curriculum at multiple levels. The parent's credentials become known to the teacher. After the initial phone call communication between the teacher and the parent was deemed to be insufficient, a face-to-face meeting was scheduled. Even though the parent made it clear that he was seeking clarification and not trying to negotiate a better mark for his son, the P.E. teacher was preparing for a heated discussion. Unbeknownst to the parent, the P.E. teacher had enlisted the assistance of two other teachers for the interview, which was taken by the parent as a clear sign of entrenchment in defense of a position (correctly or incorrectly). The parent was frustrated because the teacher (and colleagues) was defending what he, in his experience and expertise, believed was an indefensible position. Frustration on the parent side was aggravated by his perception that best practices (in a fair and equitable classroom) were not being followed. Frustration on the teacher side was aggravated both by the feeling that he had to 'dig in his heals' even though he wasn't entirely confident in his practice, and also by the fact that he was aware that the student's parent happened to be an expert in the same field.

Because the parent left somewhat frustrated and unfulfilled with the outcome, it would appear that there was no proper resolution to this scenario. Such is not the case, because the parent really was seeking clarification and not negotiating a P.E. mark for his son. Regardless of the perceived outcome of the face-to-face meeting, the teacher (and colleagues) will be forced to question their pedagogy and they may be inclined to make some changes as a result. While the parent (who is also a teacher) may be left somewhat unsatisfied with the resolution regarding his own son, he is still able to positively re-construct the interaction on a professional level. Some satisfaction is derived in his feeling that the P.E. teacher (and colleagues) will critically reflect (and perhaps re-assess) upon their teaching practice. If this is done then another potentially negative situation has led to positive growth in manner consistent with reflective teaching practice.

Scenario 3 is much shorter and simpler, which is why I am concluding with it. This scenario revolves around a short dialogue between two teachers. The first teacher is charged with a class full of students labeled as "Gifted." Often this designation comes as the result of two concomitant circumstances: 1) the student achieves a certain level on an assessment deemed to indicate the presence of 'giftedness,' and 2) the student has a parent who is a vocal advocate for their child within the school system. Such is the case with this teacher, as she spends an inordinate amount of time in direct and indirect communication with parents. One night, well past dismissal, the first teacher comments to the other regarding the frequency and length of parent/teacher meetings. The teacher, on her way to yet another parent interview simply states that it is great to finally get this parent into the school. Implicit within this reaction are a couple of prevailing attitudes: 1) although the teacher may, at times, feel overburdened by the nature, frequency, and length of parent/teacher interactions, she maintains a positive outlook, and 2) the teacher values these interaction as a way of facilitating her reflective practice. In this case the teacher of the gifted class has already taken a constructivist approach 
and she is passing it on to the other teacher through seemingly casual conversation. Teachers expect, and are expected, to commit a certain amount of their time into conversation with parents. This is normal. However this commitment can, at times, reach the level at which it becomes burdensome, and thus it can also be understood as a negative circumstance. In this scenario, the teacher of the gifted class has constructed a positive experience from what others may understand as somewhat burdensome or negative. In sharing this attitude with the other teacher, the other teacher takes a positive step forward in learning how to interpret (construct) potentially negative situations in a positive light. This is the essence of what I have attempted to explain as reflective teaching practice in a constructivist paradigm.

\section{Conclusion}

The common thread running throughout the three scenarios, and the one that I have used in order to keep a positive outlook toward what some teachers or administrators may interpret as negative interactions, is quite simple. In any given scenario that can possibly come up in the course of a career based in education - one often characterized with high emotion and unpredictability - there exists one constant variable that is always within my control. The variable that is always within my control is my emotional state in reaction to any circumstance that may arise. Even if an initial reaction to a confrontational circumstance is characterized by a heightened emotional state, that state can and should be replaced with the process of reflection and introspection. This is not to suggest that we ignore our emotions or pretend they aren't there. But there are times when the underlying issue being addressed gets buried beneath these emotions, never to re-emerge. It is to the underlying issues that we should strive to return in our reflective teaching practice. In this way what appears upon initial inspection to be negative can lead either to the affirmation of quality practice already in existence, or to the positive change of a teacher's practice in a progression toward a more desirable state. This is how difficult parents make me feel good. 


\section{References}

Bruner, J. (1996). The culture of education. Cambridge, MA: Harvard University Press.

Dewey, J. (1916). Democracy and education. New York: Macmillan.

Hargreaves, Andy \& Fullan, Michael (2012). Professional capital: Transforming teaching in every school. New York, NY: Teachers College Press.

Jaksec, Charles M. (2005). The difficult parent: An educator's guide to handling aggressive behavior. Thousand Oaks, CA: Corwin Press.

McConkey, Roy (1985). A practical guide for teachers and therapists. Cambridge, MA: Brookline Books.

Piaget, J. (1963). Cognitive development in children. Journal of research in science teaching, 2, 176-186.

Rosaldo, Renato (1993). Culture \& truth: The remaking of social analysis. Boston: Beacon Press.

Windschitl, Mark A. (2000). Constructing understanding. In P.B. Joseph, S.L. Bravmann, M.A. Windschitl, E.R. Mikel \& N.S. Green (Eds.), Cultures of curriculum (pp. 95-114). Mahwah, NJ: Lawrence Erlbaum Associates.

Vygotsky, L. S. (1979). Consciousness as a problem in the psychology of behavior. Soviet Psychology, 17(4), 3-35. 